\title{
Compound specific stable carbon isotope analysis evaluation of remediation of chlorinated volatile organic compounds at a sulfidated nanozerovalent injection field site
}

\author{
WEIBIN CHEN ${ }^{1}$ ARIEL NUNEZ GARCIA ${ }^{2}$ ElODIE \\ PASSEPORT, ${ }^{3}$ DENIS O'CARROLL ${ }^{4}$ BARBARA SHERWOOD \\ LOLLAR $^{1 *}$ \\ ${ }^{1}$ Dept. of Earth Sciences, U. of Toronto, 22 Russell Street, \\ Toronto, M5S 3B1, Canada (*correspondence: \\ barbara.sherwoodlollar@utoronto.ca) \\ ${ }^{2}$ Dept. of Civil and Env. Engineering, Western University, \\ 1151 Richmond Rd., London, Ontario, N6A 5B8, Canada \\ ${ }^{3}$ Dept of Civil and Mineral Engineering, U. of Toronto, $35 \mathrm{St}$ \\ George Street, Toronto, M5S 1A4, Canada \\ ${ }^{4}$ School of Civil and Env. Engineering, U. of New South \\ Wales, Manly Vale NSQ 2093, Australia
}

This field study evaluated the performance of an engineered sulfidated nano zerovalent iron (S-nZVI) injection to remediate various chlorinated volatile organic compounds (cVOCs). Here we report data from long-term monitoring of the site using compound specific stable carbon isotope analysis to identify degradation of the VOCs. ${ }^{13} \mathrm{C}$ enrichment, coupled with significant concentration reductions, confirms that the $\mathrm{S}$ nZVI promotes abiotic degradation of cVOCs, including 1,2-DCA (a compound commonly recalcitrant to dechlorination by conventional nZVI). The highest degree of abiotic degradation occurred 17 days after injection, with the maximum effects observed at the downgradient well that also showed the highest iron breakthrough. We discuss how CSIA can delineate the competing effects of abiotic degradation, biotic degradation, and the effects of dissolution of residual DNAPL. 